\title{
ARE THE PUBLIC FIRMS MORE INNOVATIVE THAN THE PRIVATE ONES?
}

\author{
Juan Carlos Bárcena-Ruiz*
}

\begin{abstract}
:
This paper shows that the public firms can be more innovative and, thus, more efficient than the private firms. To verify this conclusion, a mixed duopoly is considered that allows both the public firm and the private firm to adopt a new technology with a positive fixed cost that reduces the marginal cost of production. The private firm maximizes profits while the public firm maximizes the weighed sum of the consumer and producer surpluses. In this framework, it is shown that if the cost of setting up a new technology takes an intermediate value when the weight of the consumer surplus in social welfare is high enough, the public firm is more innovative than the private one. Moreover, there is at least as much innovation in a mixed duopoly as in a private duopoly if the cost of setting up a new technology is high enough.
\end{abstract}

Keywords: mixed duopoly, innovation

JEL Classification: L13, L33.

\section{Introduction}

In the late 1980s there was a consensus in Western Europe in favour of a mixed economy based on both both public and private firms. Governments created or purchased firms in a variety of sectors of the economy (including manufacturing and the service sector) for reasons that ranged from ideology to short-term strategic planning. As a result, the EU governments own a significant percentage of the firms in different sectors of industry in Europe (see Parker, 1998). The EU countries subsequently privatised some of their public firms in the 1980s and 1990s. However, a large number of firms is still owned by European governments. In this regard, although there is an empirical evidence indicating the greater efficiency of private firms relative to comparable publicly owned firms (Mueller, 1989; Vining and Boardman, 1992), there is also empirical evidence that differences in efficiency can go either way (Martin and Parker, 1997; Willner, 2001). In fact, there are successful examples of public ownership in Scandinavia (see Willner, 1998).

* Departamento de Fundamentos del Análisis Económico I. Facultad de Ciencias Económicas y Empresariales, Universidad del País Vasco, Avenida Lehendakari Aguirre, 83, 48015 Bilbao (juancarlos.barcena@ehu.es). 
Stemming from the evidence cited above, this paper analyses whether the public firms may be more efficient than the private firms or not. To that end, the paper focuses on the adoption of innovations by both private and public firms. The marginal cost of production of firms depends on their innovation level. Thus, a different degree of innovation between private and public firms is a factor that can help to explain whether or not public firms produce less efficiency than private firms. ${ }^{1}$

The objective of this paper has been focussed on a patent race in a mixed duopoly. In this respect, Delbono and Denicolo (1993) consider a patent race where only one of the firms attains the innovation. They show that in a mixed duopoly each firm invests less than in a private duopoly. Poyago-Theotoky (1998) extends the preceding analysis by considering the case of easy imitation. In that case, the research results are easy for the firm that does not own the relevant patent. It finds that when imitation is easy, in the mixed duopoly the public firm invests more in $R \& D$ than the private firm. It also finds that in the mixed duopoly the private firm reduces its $R \& D$ investment relative to the private duopoly, while the public firm spends relatively more on $R \& D$.

Instead of a patent race, firms may invest in setting up a new production plant which is certain to reduce their manufacturing unit costs. With regard to this case, Nett (1994) considers a mixed duopoly where firms have the possibility of investing in a new technology with a fixed cost, which lowers the variable cost of production (i.e. firms are involved in process innovation). He assumes that the public firm is led by a bureaucrat who wants to maximize output. However, if this bureaucrat is not able to realize at least zero-profits, he behaves as a profit-maximizer. He shows that public firms produce at a higher marginal cost than their private rivals since only the private firms innovate. Lin and Ogawa (2005) obtain a similar result assuming that to adopt the innovation has no costs. They show that if the market share of the private firms is sufficiently large only the private firm innovates.

In this paper, it is applied an extended Nett's (1994) model by considering a different objective function for the public firm: the weighed sum of the consumer and producer surpluses. ${ }^{2}$ The adoption of an innovation has a positive effect for firms. If the fixed cost of the innovation is ignored, when the private firm innovates, its profit increases due to the reduction in the marginal cost of production caused by the innovation. Similarly, the adoption of the innovation increases the consumer surplus and it can increase the producer surplus; as a result, the weighed welfare rises. However, the fixed cost of the innovation is a negative incentive to innovate.

It is argued that when the fixed cost of the innovation is low enough both firms adopt the new technology since the positive incentive to innovate is stronger than the negative one in both firms. When the fixed cost of the innovation is high enough the opposite result is obtained. In these two cases, the public and private firms are equally efficient. For the remainder of the fixed cost of the innovation only one firm innovates. In this case, it is not profitable for both firms to innovate because it increases market competition too much.

1 There are other reasons why private firms may produce at a lower cost than public firms. For example, the owner of a private firm may have better information than the public owner about the true costs of the firm (Bös and Peters, 1995), and public firms may pay higher wages (De Fraja, 1993; Willner, 1999).

2 See, for example, Matsumura (1998) and Bárcena-Ruiz and Garzón (2005). 
When the fixed cost of the innovation takes an intermediate value and the weight of consumer surplus in social welfare is great enough, only the public firm innovates. As a result, the public firm is more efficient than the private firm. In this case, the output level of the public firm is high enough. Therefore, the private firm is not interested in adopting the new technology since the competition in the product market would be excessively high, which would harm its profits. When the fixed cost of the innovation takes an intermediate value and the weight of consumer surplus in social welfare is low enough, only the private firm innovates, making it more efficient than the public firm. In this case, if the public firm innovates the private firm does not innovate, as the increase in the output of industry is high enough.

In the case of a private duopoly, if the fixed cost of the innovation is low enough, both firms innovate; if it is high enough neither firm innovates. For intermediate values of the fixed cost of the innovation, the adoption of the new technology by a single firm induces a greater profit for the firm that adopts the technology, at the expense of the other firm's profit. Thus, the positive effect offsets the negative one in the firm that innovates. As a result, only one firm adopts the cost-saving technology. In this case there are two equilibria since, given the symmetry of the model, either of the firms can innovate. ${ }^{3}$

Comparing the mixed and private duopolies it is found out that there is at least as much innovation in the private duopoly as in the mixed duopoly if the fixed cost of the innovation is low enough. In general, there is at least as much innovation in the mixed duopoly as in the private duopoly if the fixed cost of the innovation is high enough.

The rest of the paper is organised as follows. Section 2 presents the model. Section 3 considers a mixed duopoly. Section 4 analyses a private duopoly. Section 5 compares the results for these two cases. Finally, conclusions are drawn in Section 6.

\section{The Model}

A single industry is considered consisting of two firms that produce a homogeneous good. One firm is publicly owned and the other firm is private, and they are denoted, respectively, by 0 and 1 . Both firms have a constant marginal cost of production $c$. These firms can adopt a new technology, with a fixed cost $F$, which reduces the marginal cost of production. With no loss of generality the marginal cost of production of the new technology is normalized to zero. Inverse demand function is assumed to be linear and is given by:

$$
p=a-q_{0}-q_{1}, a>6 c,^{4}
$$

where $p$ is the price for the good and $q_{i}$ is the amount of the good produced by firm $i$. The profit of firm $i$ is given by:

$$
\pi_{i}=\left(a-q_{i}-q_{j}-c_{i}\right) q_{i}-F_{i}, i \neq j ; i, j=0,1,
$$

where $c_{i} \in\{0, c\}$ and $F_{i} \in\{0, F\}$.

3 This result is also obtained by Bester and Petrakis (1993).

4 It is assumed that the size of the market is not low enough $(a>6 c)$ to reduce the number of possible cases that arise in the paper. This assumption does not affect the main results of the paper and permits us to simplify the exposition of the results. 
The private firm chooses the output level, $q_{1}$, that maximizes its profit given by (2) for $i=1$ and $j=0$. The objective function of the public firm is the weighed sum of the consumer and producer surpluses. Consumer and producer surpluses, respectively, are given by $C S=\frac{1}{2}\left(q_{0}+q_{1}\right)^{2}$ and $P S=\pi_{0}+\pi_{1}$. The weigted welfare is given by:

$$
W=\alpha C S+P S, \alpha_{L}<\alpha<\alpha_{H},
$$

where $\alpha_{L}=\frac{2 c}{a}$ and $\alpha_{H}=\frac{a-2 c}{a-c}$. The assumption $\alpha_{L}<\alpha<\alpha_{H}$ ensures that the two firms produce a positive output: $\alpha>\alpha_{L}$ ensures that the public firm produces a positive output level when only the private firm innovates; $\alpha<\alpha_{H}$ ensures that the private firm produces a positive output level when only the public firm innovates.

It is possible to propose a two-stage game with the following timing. In the first stage, firms decide whether to innovate or not. In the second stage, firms decide their output level. Therefore there are four cases: both firms innovate $(Y Y)$, neither firm innovates $(N N)$, only the public firm innovates $(Y N)$ and only the private firm innovates $(N Y)$. I solve the game by backward induction to obtain a subgame perfect Nash equilibrium.

I shall solve the game considering first that market structure is a mixed duopoly. Next I shall consider a private duopoly to analyse whether there is more innovation or not in a mixed duopoly than in a private duopoly.

\section{Mixed Duopoly}

I solve first the second stage of the game in which firms simultaneously decide their output levels. Private firm 1 chooses the output level, $q_{1}$, that maximizes its profit and public firm 0 chooses the output level, $q_{0}$, that maximizes weighed welfare. Solving these problems I obtain:

$$
\begin{gathered}
q_{1}=\frac{a(1-\alpha)+c_{0}-c_{1}(2-\alpha)}{2-\alpha}, q_{0}=\frac{a \alpha-2 c_{0}+c_{1}(2-\alpha)}{2-\alpha}, \\
\pi_{1}=\frac{\left(a(1-\alpha)+c_{0}-c_{1}(2-\alpha)\right)^{2}}{(2-\alpha)^{2}}-F_{1}, \pi_{0}=\frac{\left(a-c_{0}\right)(1-\alpha)\left(a \alpha-2 c_{0}+c_{1}(2-\alpha)\right)}{(2-\alpha)^{2}}-F_{0}, \\
P S=\left(a-c_{1}\right)\left(c_{0}-c_{1}\right)+\frac{\left(a-c_{0}\right)\left(a(1-\alpha)+c_{1}(2-\alpha)-c_{0}(3-2 \alpha)\right)}{(2-\alpha)^{2}}-F_{0}-F_{1}, \\
C S=\frac{\left(a-c_{0}\right)^{2}}{2(2-\alpha)^{2}}, W=\frac{\left(a+2 c_{1}-3 c_{0}\right)\left(a-c_{0}\right)}{2(2-\alpha)}+\left(a-c_{1}\right)\left(c_{0}-c_{1}\right)-F_{0}-F_{1} .
\end{gathered}
$$

When both firms innovate, I obtain (4) for $c_{1}=c_{0}=0$ and $F_{1}=F_{0}=F$. When neither firm innovates, I obtain (4) for $c_{1}=c_{0}=c$ and $F_{1}=F_{0}=0$. When only the public firm innovates 
I obtain (4) for $c_{1}=c, c_{0}=0, F_{1}=0$, and $F_{0}=F$. Finally, when only the private firm innovates I obtain (4) for $c_{1}=0, c_{0}=c, F_{1}=F$, and $F_{0}=0$.

Solving the first stage of the game, the following result is obtained. Zone $I$ groups the values of parameters, such that $F \leq \min \left\{F_{W 1}, F_{\pi 1}\right\}$. Zone $I I$ is formed by the values of parameters, such that $F \geq \max \left\{F_{W 2}, F_{\pi 2}\right\}$. Zone $I I I$ groups the values of parameters, such that $F_{\pi 1} \geq F>F_{W 1}$ or if $\max \left\{F_{W 2}, F_{\pi 1}\right\}<F<F_{\pi 2}$. Zone $I V$ groups the values of parameters, such that $\min \left\{F_{W 2}, F_{\pi 2}\right\} \geq F>\max \left\{F_{W 1}, F_{\pi 1}\right\}$. Finally, zone $V$ groups the values of parameters, such that $F_{W 1} \geq F>F_{\pi 1}$ or if $F_{W 2}>F>\min \left\{F_{W 1}, F_{\pi 2}\right\}$. The values of $F_{\pi i}$ and $F_{W i}(i=1,2)$ are relegated to Appendix 1.

Proposition 1. In the mixed duopoly, both firms innovate in zone I. Neither firm innovates in zone II. For the remainder of the values of parameter F only one firm innovates. Only the private firm innovates in zone III. There are two equilibria in zone IV: in one of them it is the public firm that innovates and in the other it is the private firm. Finally, in zone $V$, only the public firm innovates.

Proof. See Appendix 1.

The result shown in Proposition 1 is illustrated in Figure 1. This proposition shows that, in equilibrium, the public firm can innovate more than, the same extent as or less than the private firm.

Figure 1

Illustration of Proposition 1

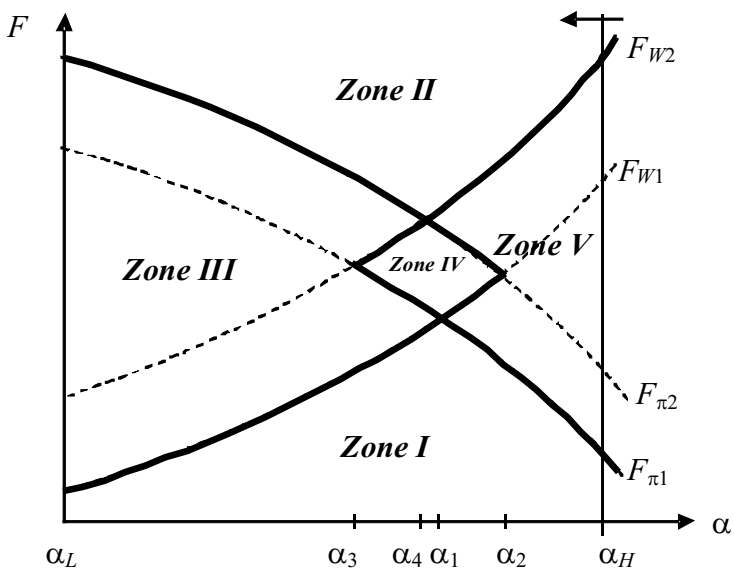

If the adoption of the new technology does not require any investment $F$, then $\pi^{Y Y}>\pi^{Y N}$ and $\pi^{N Y}>\pi^{N N}$. Therefore, the private firm will always innovate independently of whether the public firm innovates or not. The adoption of the innovation reduces the marginal cost of production of the private firm, which increases its profits. On the other hand, $W^{Y Y}>W^{N Y}$ and $W^{Y N}>W^{N N}$, which means that the public firm innovates independently of whether the private firm innovates or not. When the public firm innovates the consumer surplus rises: $C S^{Y Y}>C S^{N Y}$ and $C S^{Y N}>C S^{N N}$. Moreover, $P S^{Y Y}>P S^{N Y}$ if and only if $a>\frac{c(3-2 \alpha)}{\alpha(1-\alpha)}$ and $P S^{Y N}>P S^{N N}$. Therefore, if the private firm does not innovate the pub- 
lic firm innovates since both the consumer and producer surpluses increase. If the private firm adopts the new technology, the public firm innovates since the increase in the consumer surplus offsets the possible decrease in the producer surplus. Therefore, if the adoption of the new technology does not require any investment, both the public firm and the private firm have a positive incentive to innovate. By contrast, the fixed cost $F$ is a negative incentive to innovate.

When the fixed cost of the innovation, $F$, is low enough (Zone $I$ ) both firms adopt the new technology. Given that $F$ is low enough, the positive incentive to innovate is stronger than the negative one in both firms. When $F$ is high enough (Zone $I I$ ) neither firm adopts the new technology. In this case, the negative incentive to innovate is stronger than the positive one in both firms. In these two cases the two firms are equally efficient.

For the remainder of the values of $F$ (Zones $I I I, I V$ and $V$ ) only one firm innovates. It is not profitable for both firms to innovate because it increases market competition excessively, which would negatively affect both the profit of the private firm and the producer surplus. In this case, the firm that innovates has a lower marginal cost of production than the other one and is thus more efficient.

When $F$ takes an intermediate value and $\alpha$ is high enough (Zone $V$ ), only the public firm innovates (see Figure 1). In this case, as $\alpha$ is high enough the weight of the consumer surplus in the objective function of the public firm is also high enough. As the output of the public firm increases with $\alpha$ it is high enough in this zone. Therefore, if the public firm innovates the private firm does not adopt the new technology since the competition in the product market would be excessively high, which would harm its profits. As a result, this firm finds it unprofitable to pay the cost of the innovation. If the private firm does not innovate, the public firm adopts the new technology to increase market competition.

When $F$ takes an intermediate value and $\alpha$ is low enough (Zone $I I I$ ), only the private firm innovates (see Figure 1). In this case, as $\alpha$ is low enough the weight of the consumer surplus in the objective function of the public firm is also low enough. If the private firm innovates it increases the output of industry and, thus, the consumer surplus. As market competition is great enough the public firm does not innovate. If the public firm does not innovate, the private firm adopts the new technology to gain greater market share and profits.

Finally, when both $F$ and $\alpha$ take an intermediate value (Zone $I V$ ), there are two asymmetric equilibria. In one of them the public firm innovates, and in the other the private firm does so.

In order to analyse whether there is more innovation in a mixed duopoly than in a private duopoly I consider that both firms are privately owned.

\section{Private Duopoly}

I solve first the second stage of the game in which firms simultaneously decide their output level. Private firm $i$ chooses the output level, $q_{i}$, that maximizes its profit $(i=1,2)$. Solving these problems I obtain:

$$
q_{i}=\frac{a-2 c_{i}+c_{j}}{3}, \pi_{i}=\frac{\left(a-2 c_{i}+c_{j}\right)^{2}}{9}-F_{i}, i \neq j ; i, j=0,1 .
$$


When both firms innovate, I obtain (5) for $c_{i}=0$ and $F_{i}=F, i=0,1$. When neither firm innovates, I obtain (5) for $c_{i}=c$ and $F_{i}=F, i=0,1$. When only firm $i$ innovates I obtain (5) for $c_{j}=c, c_{i}=0, F_{j}=0$ and $F_{i}=F, i \neq j ; i, j=0,1$.

Solving the first stage of the game we obtain that $\pi^{Y Y}>\pi^{Y N}$ if and only if $F<F_{P 1}$ and $\pi^{N Y}>\pi^{N N}>$ if and only if $F<F_{P 2}$, where $F_{P 1}=\frac{4 c(a-c)}{9}, F_{P 2}=\frac{4 a c}{9}, F_{P 2}>F_{P 1}$. Therefore, the following result is obtained.

Lemma 1. In the private duopoly, if $F \geq F_{P 2}$ neither firm innovates, if $F_{P 2}>F>F_{P 1}$ only one firm adopts the new technology and, finally, if $F \leq F_{P 1}$ both firms innovate.

If the adoption of the innovation does not require any fixed $\operatorname{cost} F$ to be paid, then $\pi^{Y k}>\pi^{N k}(k=Y, N)$, which reflects a positive incentive to innovate since the profit of a given firm is greater if it innovates independently of the decision taken by its rival. However, if the adoption of the new technology requires an investment, different values of parameter $F$ will produce different results in equilibrium. If $F$ is low enough $\left(F \leq F_{P 1}\right)$, both firms innovate since the positive incentive to innovate is stronger than the negative one (the fixed $\operatorname{cost} F)$ in both firms. If $F$ is high enough $\left(F \geq F_{P 2}\right)$, the opposed result is obtained. For intermediate values of $F\left(F_{P 2}>F>F_{P 1}\right)$, the adoption of the new technology by a single firm induces a greater profit (without considering the fixed $\operatorname{cost} \mathrm{F}$ ) for the firm that adopts this technology, at the expense of the other firm's profit. Thus, the positive effect offsets the negative one in the firm that adopts a new technology. As a result, only one firm adopts the cost-saving technology. In this case, there are two equilibria since, given the symmetry of the model, either of the firms can innovate. It has to be noted that, as both firms are private, the result obtained in lemma 1 does not depend on parameter $\alpha$.

\section{Comparison of Results}

In this section I compare the results obtained in the mixed and private duopolies. From Proposition 1 and Lemma 1 the following result is obtained. Let $a^{* *}=\frac{3 c}{4}(13+\sqrt{157})$, $a^{*}=\frac{c}{4}(23+\sqrt{469})$, where $a^{* *}>a^{*}$.

Proposition 2. If $F<F_{P 1}$ there is at least as much innovation in the private duopoly as in the mixed duopoly. If $F \geq F_{P 1}$ there is at least as much innovation in the mixed duopoly as in the private duopoly with the exception of the case $F_{P 1}<F<\min \left\{F_{W 1}, F_{\pi 1}\right\}$ when $a>a^{*}$; in this last case there is more innovation in the private duopoly.

Proof. See Appendix 2.

The result shown in proposition 2 is illustrated in Figure 2 for the case $a>a^{* *}$. In Figure 2, superscript $M$ denotes the mixed duopoly and superscript $P$ denotes the private duopoly. To explain this result, it has to be noted that the symmetry of the model means that in the private duopoly neither firm has an advantage over the other. However, in the mixed duopoly there is an asymmetry that can give one firm an advantage over the other. If parameter $\alpha$ is low (high) enough, the weight of the consumer surplus in the weighed welfare is low (high) enough and, thus, the output level of the public firm is also low 
(high) enough which gives an advantage (a disadvantage) to the private firm. This means that the firm that has an advantage (a disadvantage) in the mixed duopoly innovates for a higher (lower) value of $F$ in the mixed duopoly than in the private duopoly.

Figure 2

Illustration of Proposition 2
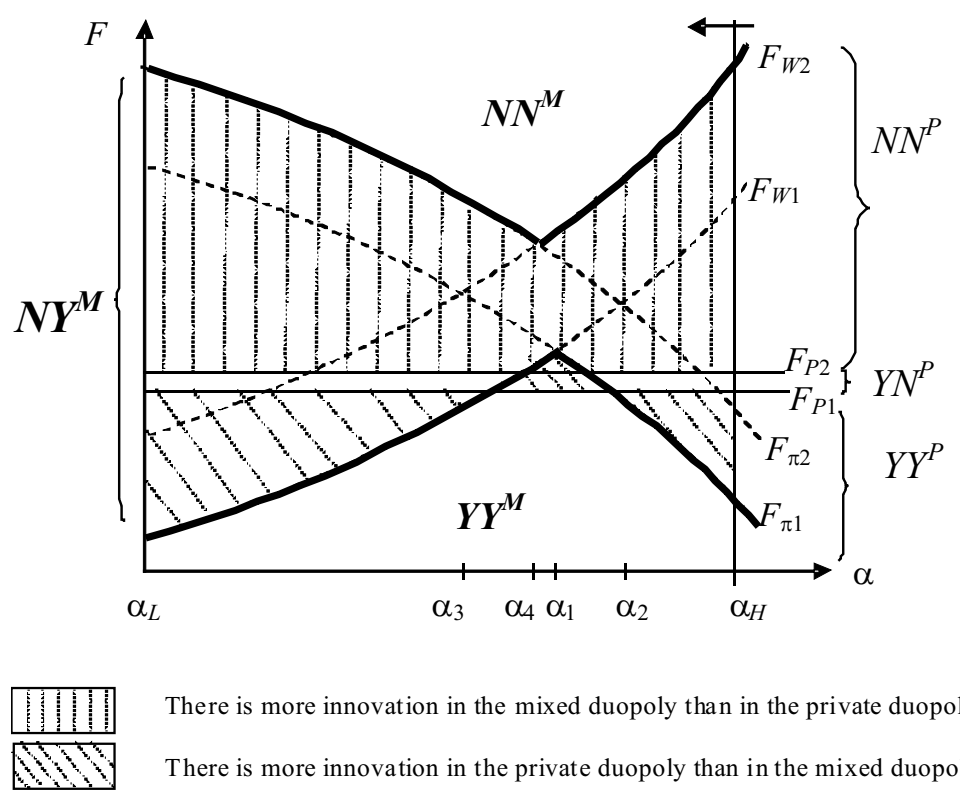

There is more innovation in the mixed duopoly than in the private duopoly.

There is more innovation in the private duopoly than in the mixed duopoly.

If $\min \left\{F_{W 1}, F_{\pi 1}\right\} \leq F<F_{P 1}$, there is more innovation in the private duopoly (see Figure 2). In this zone, both firms innovate in the private duopoly but only one firm innovates in the mixed duopoly. As shown in Lemma 1, both firms innovate in the private duopoly if $F$ is low enough $\left(F<F_{P 1}\right)$. In the mixed duopoly, there is greater market competition than in the private duopoly since the objective function of the public firm takes into account the consumer surplus (and, thus, the total output of industry). As a result, only one firm innovates in this zone.

If $F_{P 2}<F \leq \max \left\{F_{W 2}, F_{\pi 2}\right\}$ with the exception of the case $F_{P 1}<F<\min \left\{F_{W 1}, F_{\pi 1}\right\}$ when $a>a^{* *}$, there is more innovation in a mixed duopoly than in a private one (see Figure 2). In this zone, neither firm innovates in the private duopoly since $F$ is high enough. However, in this zone one firm innovates in the mixed duopoly. The firm that has an advantage innovates for higher values of parameter $F$ in the mixed duopoly than in the private duopoly.

Depending on the parameters of the model (see Appendix 2), there are two additional cases. If the size of the market is such that $a^{* *}>a>a^{*}$ when $F_{P 1}<F \leq \min$ $\left\{F_{W 1}, F_{\pi 1}\right\}$, both firms innovate in the private duopoly and only one firm innovates in the mixed one. If $a>a^{* *}$ when $F_{P 1}<F \leq \min \left\{F_{W 1}, F_{\pi 1}\right\}$, both firms innovate in the private duopoly and neither firm innovates in the mixed duopoly. 


\section{Conclusions}

This paper analyses whether or not public firms innovate more than private firms. It is considered that firms may invest in a new technology with a fixed cost, which lowers the variable cost of production. The objective function of the public firm is the weighed sum of the consumer and producer surpluses. It is obtained that when the fixed cost of the innovation takes an intermediate value and the weight of consumer surplus in social welfare is great enough, only the public firm innovates. In this case, the public firm is more efficient than the private firm. However, when the fixed cost of the innovation takes an intermediate value and the weight of consumer surplus in social welfare is low enough, only the private firm innovates. In this case, the private firm is more efficient than the public firm.

In the case of a private duopoly, for intermediate values of the fixed cost of the innovation, only one firm adopts the cost-saving technology. In this case there are two equilibria since, given the symmetry of the model, either of the firms can innovate.

Comparing the mixed and private duopolies it is obtained that there is at least as much innovation in the private duopoly as in the mixed duopoly if the fixed cost of the innovation is low enough. In general, there is at least as much innovation in the mixed duopoly as in the private duopoly if the fixed cost of the innovation is high enough.

\section{Acknowledgements}

Financial support from Ministerio de Ciencia y Tecnología and FEDER (BEC2003-04430, SEJ2006-05596) and UPV (Subvención a grupos) is gratefully acknowledged.

\section{Appendix 1}

From (4), the following results are obtained:

i) $\pi^{Y Y}>\pi^{Y N}$ if and only if $F<F_{\pi 1}$ and $\pi^{N Y}>\pi^{N N}$ if and only if $F<\mathrm{F}_{\pi 2}, F_{\pi 1}<\mathrm{F}_{\pi 2}$, where $F_{\pi 1}=$ $\frac{c(2 a(1-\alpha)-c(2-\alpha))}{2-\alpha}$ and $\mathrm{F}_{\pi 2}=\frac{c(2 a(1-\alpha)+c \alpha)}{2-\alpha}$.

ii) $W^{Y Y}>W^{N Y}$ if and only if $F<F_{W 1}$ and $W^{Y N}>W^{N N}$ if and only if $F<F_{W 2}, F_{W 1}<F_{W 2}$, where $\mathrm{F}_{W 1}=\frac{c(2 a \alpha-3 c)}{2(2-\alpha)}$ and $F_{W 2}=\frac{c(2 a \alpha+c(3-2 \alpha))}{2(2-\alpha)}$.

Taking into account $(i)$ and (ii), the result shown in Proposition 1 is obtained, as illustrated in Figure 1. In order to plot Figure 1, it is necessary to show that $F_{\pi i}$ decreases with $\alpha$, while $F_{W i}$ increases with $\alpha$ :

$$
\begin{gathered}
\frac{\partial F_{\pi 1}}{\partial \alpha}=-\frac{2 a c}{(2-\alpha)^{2}}<0, \quad \frac{\partial F_{\pi 2}}{\partial \alpha}=-\frac{2 c(a-c)}{(2-\alpha)^{2}}<0, \\
\frac{\partial F_{W 1}}{\partial \alpha}=\frac{c(4 a-3 c)}{2(2-\alpha)^{2}}>0, \frac{\partial F_{W 2}}{\partial \alpha}=\frac{c(4 a-c)}{2(2-\alpha)^{2}}>0 .
\end{gathered}
$$


On the other hand, it can be shown that $F_{W 1}>F_{\pi 1}$ if and only if $\alpha>\alpha_{1}, F_{W 1}>F_{\pi 2}$ if and only if $\alpha>\alpha_{2}, F_{W 2}>F_{\pi 1}$ if and only if $\alpha>\alpha_{3}, F_{W 2}>F_{\pi 2}$ if and only if $\alpha>\alpha_{4} ; \alpha_{H}>\alpha_{2}>\alpha_{1}>\alpha_{4}$ $>\alpha_{3}>\alpha_{L}$, where $\alpha_{1}=\frac{4 a-c}{2(3 a-c)}, \alpha_{2}=\frac{4 a+3 c}{2(3 a-c)}, \alpha_{3}=\frac{4 a-7 c}{2(3 a-2 c)}$, and $\alpha_{4}=\frac{4 a-3 c}{2(3 a-2 c)}$.

\section{Appendix 2}

In order to prove Proposition 2 it is necessary to check the following.

When $\alpha=\alpha_{\mathrm{L}}: F_{\pi 1}>F_{P 2}>F_{P 1}>F_{W 2}$.

i) $F_{\pi 1}-F_{P 2}=\frac{c\left(5 a^{2}-23 a c+9 c^{2}\right)}{9(a-c)}>0$ since $a>6 c$.

ii) It is shown in Appendix 1 that $F_{P 2}>F_{P 1}$.

iii) $F_{P 1}-F_{W 2}=\frac{c\left(16 a^{2}-95 a c+52 c^{2}\right)}{36(a-c)}>0$ since $a>6 c$.

When $\alpha=\alpha_{H}: F_{W 1}>F_{P 2}>\max \left\{F_{P 1}, F_{\pi 2}\right\}$.

i) $F_{W 1}-F_{P 2}=\frac{c\left(10 a^{2}-63 a c+27 c^{2}\right)}{18 a}>0$ since $a>6 c$.

ii) $F_{P 2}-F_{\pi 2}=\frac{(a-6 c)(4 a-3 c)}{9 a}>0$ since $a>6 c$.

iii) $F_{P 1}-F_{\pi 2}=\frac{c\left(4 a^{2}-31 a c+18 c^{2}\right)}{9 a}>0$ if and only if $a>\frac{c}{8}(31+\sqrt{673})$.

When $\alpha=\alpha_{3}: F_{W 2}=F_{\pi 1}>F_{P 2}$.

i) $F_{\pi 2}-F_{P 2}=\frac{c\left(4 a^{2}+38 a c-27 c^{2}\right)}{9(8 a-5 c)}>0$.

When $\alpha=\alpha_{1}: F_{W 1}=F_{\pi 1}>F_{P 2}$ if and only if $a>a^{* * ;} F_{W 1}=F_{\pi 1}>F_{P 1}$ if and only if $a>a^{*}$, where $a^{* *}>a^{*}$.

i) $F_{W 1}-F_{P 2}=\frac{c\left(4 a^{2}-78 a c+27 c^{2}\right)}{9(8 a-3 c)}>0$ if and only if $a>a^{* *}=\frac{3 c}{4}(13+\sqrt{157)}$.

ii) $F_{W 21}-F_{P 1}=\frac{c\left(4 a^{2}-46 a c+15 c^{2}\right)}{9(8 a-3 c)}>0$ if and only if $a>a^{*}=\frac{c}{4}(23+\sqrt{469})$.

From these results, the result shown in Proposition 2 is obtained, as illustrated in Figure 2 for the case $a>a^{* *}$.

\section{References}

Bárcena-Ruiz, J. C., Garzón, M. B. (2005), "Economic Integration and Privatisation under Diseconomies of Scale". European Journal of Political Economy, 21, pp. 247-267.

Bester, H., Petrakis, E. (1993), "The Incentives for Cost Reduction in a Differentiated Industry". International Journal of Industrial Organization, 11, pp. 519-534.

Bös, D., Peters, W. (1995), "Double Inefficiency in Optimally Organized Firms". Journal of Public Economics, 53, pp. 355-375.

De Fraja, G. (1993), "Unions and Wages in Public and Private Firms: A Game-Theoretic Analysis". Oxford Economic Papers, 45, pp. 457-469. 
Delbono, F., Denicolo, V. (1993), "Regulating Innovative Activity. The Role of a Public Firm". International Journal of Industrial Organization, 11, pp. 35-48.

Lin, H. L., Ogawa, H. (2005), "Cost Reducing Incentives in a Mixed Duopoly Market". Economics Bulletin, 12, 6, pp. 1-6.

Martin, S., Parker, D. (1997), The Impact of Privatization: Ownership and Corporate Performance in the U.K. London: Routledge.

Matsumura, T. (1998), "Partial Privatization in Mixed Duopoly". Journal of Public Economics, 70, pp. 473-483.

Mueller, D. C. (1989), Public Choice II. Cambridge, UK: Cambridge University Press.

Nett, L. (1994), "Why Private Firms Are More Innovative than Public Firms". European Journal of Political Economy, 10, pp. 639-653.

Parker, D., ed. (1998), Privatisation in the European Union. Theory and Policy Perspectives. London and New York: Routledge.

Poyago-Theotoky, J. (1998), "R\&D Competition in a Mixed Duopoly under Uncertainty and Easy Imitation". Journal of Comparative Economics, 26, pp. 415-428.

Vining, A., Boardman, A. (1992), "Ownership vs. Competition: Efficiency in Public Enterprise". Public Choice, 73, pp. 205-239.

Willner, J. (1998), "Privatization in Finland, Sweden and Denmark - Fashion or Necessity?", in Parker, D., ed., Privatization in the European Union. Theory and Policy Perspectives. London: Routledge, pp. $172-190$.

Willner, J. (1999), "Policy Objectives and Performance in a Mixed Market with Bargaining". International Journal of Industrial Organization, 17, pp. 137-145.

Willner, J. (2001), "Ownership, Efficiency and Political Interference". European Journal of Political Economy, 17, pp. 723-748. 